\title{
Air leakage modelling and its influence on the air quality inside a garage
}

\author{
Nina Szczepanik-Ścisło ${ }^{1, *}$, and Łukasz Ścisło ${ }^{2}$ \\ ${ }^{1}$ Department of Environmental Engineering, Cracow University of Technology, 24 Warszawska str. \\ 31-155 Krakow, Poland. \\ ${ }^{2}$ Department of Electrical and Computer Engineering, Cracow University of Technology, \\ 24 Warszawska str. 31-155 Krakow, Poland.
}

\begin{abstract}
The problem of poor air quality due to increased airtightness of dwellings is a growing global problem. What is more, studies have shown that leakages of contaminants from garages occur to the attaching buildings. For these reasons to topic of the study was to see how increased airtightness influenced the air quality of a garage attached to a house and how it affected the contaminant flow into the house. The garage was equipped with an outlet mechanical vent. Three cases were taken under consideration: without any additional sealing, using a gasket on the garage door and using a gasket on both the garage and house door. The results of the study showed that the increased airtightness increases the concentration of contaminants inside the garage as well as the $\mathrm{CO}_{2}$ concentration flowing into the house. The air flow was disturbed and the contaminants did not flow freely to the outlet causing their dispersion inside of the garage. Such situations may be harmful to human health and should be prevented.
\end{abstract}

\section{Introduction}

Energy savings are a growing trend thought the globe. As the building sector has become the largest energy consuming sector followed closely by transport and industry [1], more and more regulations are being introduced to lower this sectors carbon footprint. In Europe the control of energy use of new buildings is being limited by directives that require that all new buildings in the European Union must be nearly zero energy buildings from $31^{\text {st }}$ December 2020 and public buildings must be nearly zero energy buildings from $31^{\text {st }}$ December 2018 [2]. These regulations as well as growing energy prices are setting a trend to build more energy efficient dwellings. This also concerns all types of buildings, from small houses to large offices and aims for energy savings while maintaining proper indoor air comfort.

To maintain proper IAQ (indoor air quality), research and improvements of ventilation systems should go alongside the development of energy efficient buildings as the quality of the air affects the condition of occupants. If it is not maintained it may lead to lack of concentration, dizziness, tiredness and lower the occupants' productivity.

\footnotetext{
* Corresponding author: nszczepanik@pk.edu.p1
} 
Studies have also shown the link between contaminant concentration and the application of an attached garage. It can be a significant contaminant contributor to the indoor environment [3-5]being the source of not only carbon dioxide but also, among other contaminants like carbon monoxide, volatile organic compounds (VOC) [6], benzene and nitrogen dioxide. Nirvan et al. [3] undertook studies concerning the contaminants from a garage of a house using computer simulations. Studies showed that high concentration of indoor pollutants for typical leaky garage-house interface within the house. The simulations demonstrated that for most cases, the contaminant entry rate by the depressurization due to the exhaust ventilation results in higher contaminant concentrations in the living area. Batterman et al. [7] studied the concentration of VOC within 15 residential garages in Michigan that varied in type, size, use and other characteristics. Nearly all of the garages in the study showed high VOC levels, largely due to the evaporation of gasoline. Additional emission sources identified included paints, solvents, and oils. Papakonstantinou et al. [8] studied the influence of carbon monoxide on occupants in an underground garage. The results showed that only under the proper ventilation conditions the levels of $\mathrm{CO}$ concentration decrease and remain below the health based indoor air quality criteria. Otherwise, the air quality rapidly decreased and was unfit for occupants. GładyszewskaFiedoruk and Nieciecki [9] also conducted a study on the influence of cars in a multi-car garage. They studied the influence of vehicles on the concentration of carbon monoxide and carbon dioxide. Fortunately, their study showed that the recorded concentrations of $\mathrm{CO}$ as well as $\mathrm{CO}_{2}$ were below the maximum recommended levels.

This paper presents the results of contaminant simulations, inside of a tested garage and the influence of the garage on the air quality within an attached house. Most garages that have a ventilation system are equipped only with an outlet vent, and fresh air is provided by the leakages through the garage door. However there is a risk that due to enhanced airtightness, the ventilation system may not provide proper IAQ.

The accumulation of contaminants due to the objects airtightness may cause a threat for the occupants as they can risk prolonged contaminant exposure leading to harmful consequences for their health. For this reason, the focus of this paper is set on the IAQ of a garage that has enhanced airtightness for energy saving purposes and is connected to a detached house.

\section{Methods}

The study focused on a garage that was connected to a detached house. The garage had the volume of $75 \mathrm{~m}^{3}$ and was equipped with an outlet vent with the capacity of $55 \mathrm{l} / \mathrm{s}$ [10]. The fresh air was supplied by the leakages in the garage door. It was attached to the house at the same level and was connected through a door that was assumed to be shut during the simulation. The layout of the garage in the simulation program is shown in figure 1. Only half of the garage was uploaded to the simulation program with the symmetry option used. This was done to lower the number of nodes and cells inside during the simulation. 


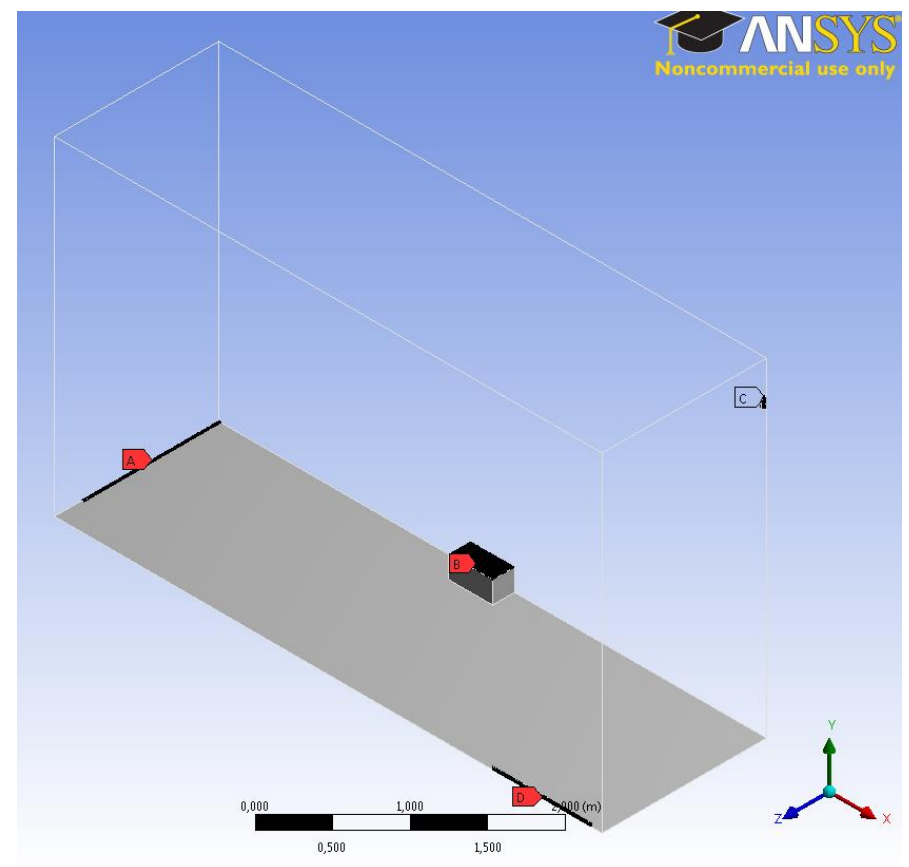

Fig. 1. Wall frame of the garage in the AnsysFluent tool: A - inlet of fresh air though the garage door, $\mathrm{B}$ - contaminant source, $\mathrm{C}$ - outlet vent, $\mathrm{D}$ - outlet though the closed door in the garage.

The test of the airtightness was conducted using the AnsysFluent simulation program. The program has been used by researchers to determine the quality of indoor air and pollutant concentrations [11]. Hajji et al. [12] used the AnsysFluent software to study the behaviour and natural ventilation of hydrogen during an accidental leak inside a residential garage. Similar research was conducted by $\mathrm{He}$ et al. [12], who used the Fluent software to predict the concentration of hydrogen in a partially confined space. Montazeri and Montazeri [13] used the program for the evaluation of the impact of the outlet openings on the ventilation performance of a single-zone isolated building with a wind catcher, while Assaad et al. [14] used Fluent study to performance of an intermittent periodic personalized ventilation coupled with mixing ventilation and its ability to protect occupants from contaminants. These studies show that the program is capable of reflecting the influence of a garage on the IAQ inside of a house as well as detailed airflows and contaminant concentration. For these reasons it was chosen for the study.

To study the influence of the air tightness on the IAQ of the test object, three different cases where taken under consideration:

- Both the door to the garage and the house had leakages;

- The garage door was sealed with a gasket to minimize airflow through the garage;

- Both the garage door and the door to the house had gaskets installed.

This was done to determine how the leakages influence the air quality inside of the garage and how the contaminants flow through the door into the house.

The outdoor air consisted of $0.04 \%$ of carbon dioxide, $21.00 \%$ oxygen and $78.96 \%$ nitrogen. The stream of $\mathrm{CO}_{2}$ generated by the car which was assumed to be the contaminant source inside of the garage was $0.5 \mathrm{~g} / \mathrm{s}[8,15]$. 


\section{Results}

\subsection{No gaskets}

The result of the simulation where no gasket was used and the airflow is not disrupted is shown in figures 2 and 3. The average concentration that is on the centre of the symmetry of the garage and $1.8 \mathrm{~m}$ above the ground (on the height of a grown humans head) is equal to around 1050 PPM. With the maximum hygienic level being 1000 PPM, this configuration is safe for the occupant, as the maximum concentration is only slightly elevated. Figure 1 also shows that the contaminant flows freely toward the outlet vent meaning that it is removed sufficiently by the ventilation system.

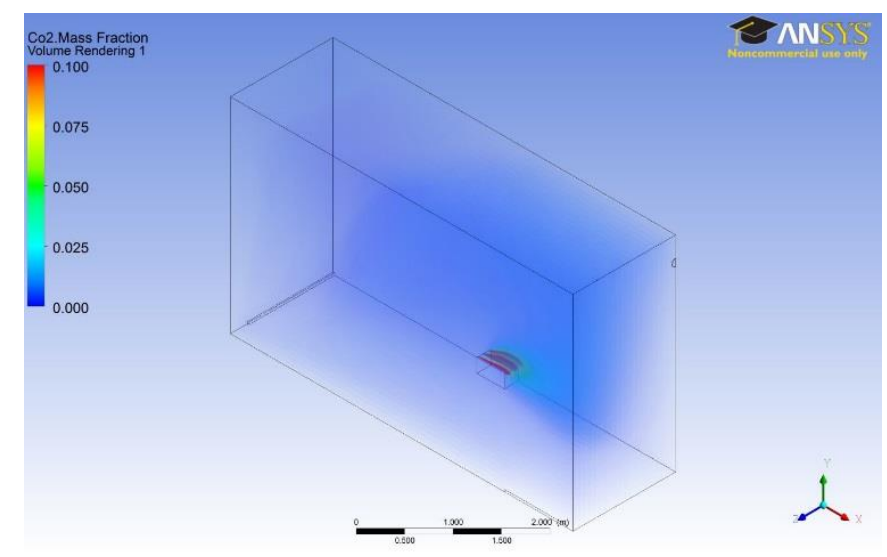

Fig. 2. Results of the $\mathrm{CO}_{2}$ concentration inside of the garage - no gasket.

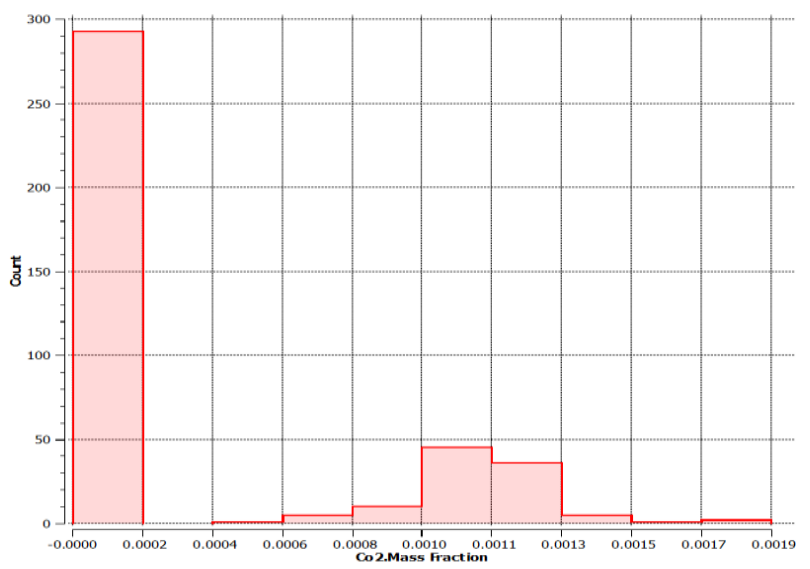

Fig. 3. Leakage of $\mathrm{CO}_{2}$ into the house though the door.

The results from figure 3 show the amount of $\mathrm{CO}_{2}$ leaking into the house through the door. The average leaking in this case is equal to $0.001 \mathrm{~kg} / \mathrm{kg} \mathrm{CO}$ which is equal to around 660 PPM. The default concentration of the outdoor air was assumed to be 400 PPM meaning that only the additional 260 PPM flow into the house. The contaminant level in the 
garage as well as the one flowing into the house is safe for the occupants and the ventilation system removes the additional load of $\mathrm{CO}_{2}$ generated from the car.

\subsection{Gasket on the garage door}

The results of the simulation where the gasket was placed on the garage door are shown in figures 4 and 5 . The average concentration that is on the centre of the symmetry of the garage and $1.8 \mathrm{~m}$ above the ground (on the height of a grown humans head) is equal to around 3280 PPM. Such concentration is higher than the maximum hygienic level and may lead to problem for occupants with respiratory problems when the occupant will be exposed $[16,17]$. The conditions in the garage are not safe for the occupants and they should not stay in such conditions for long periods of time.

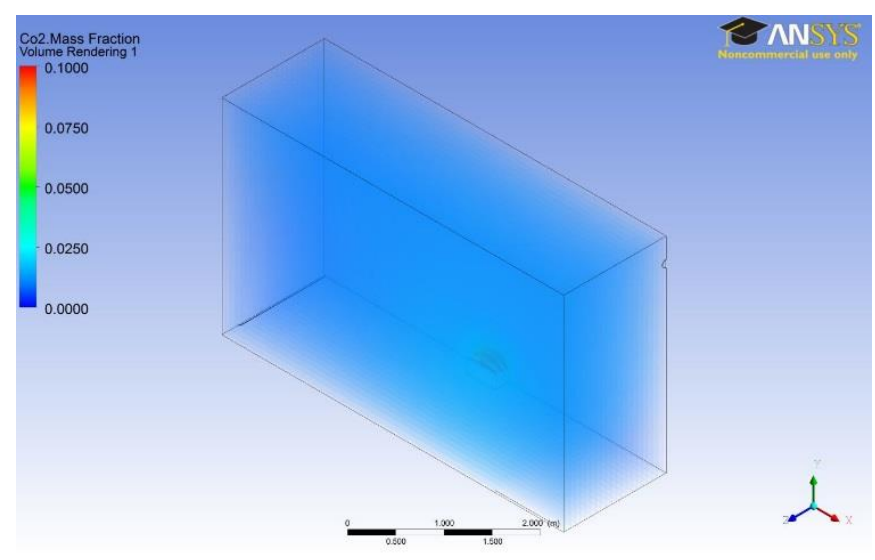

Fig. 4. Results of the $\mathrm{CO}_{2}$ concentration inside of the garage -gasket on the garage door.

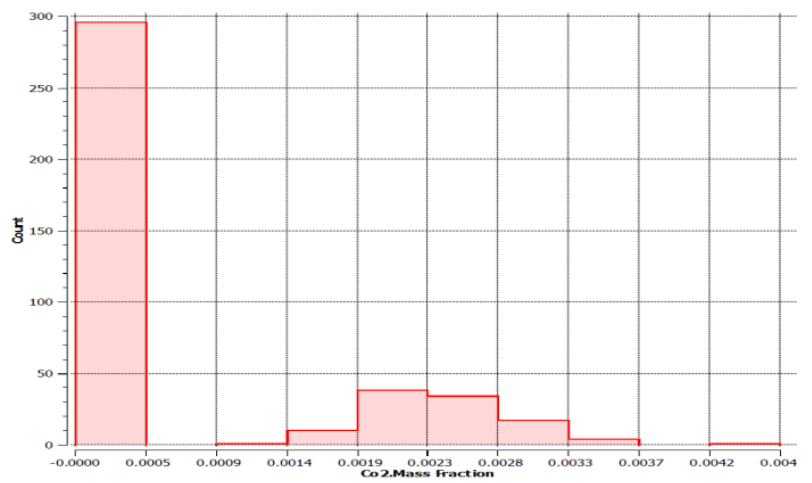

Fig. 5. Leakage of $\mathrm{CO}_{2}$ into the house though the door - gasket on the garage door.

The results from figure 5 show the amount of the contaminant leaking into the house though the door when the gasket was installed. The results show that the average leaking in this case is equal to $0.0022 \mathrm{~kg} / \mathrm{kg} \mathrm{CO} 2$ which is equal to around $1440 \mathrm{PPM}$. High concentrations of the contaminant will flow into the building coursing the rise of the $\mathrm{CO}_{2}$ level in the house that can be potentially dangerous. Additional sources of $\mathrm{CO}_{2}$ in the house 
e.g. from human respiration or cooking combined with the flow from the garage may cause contaminant accumulation effecting the occupants.

\subsection{Gasket on the garage door and door to the house}

The results of the simulation where the gasket was placed both on the garage door and house door are shown in figures 6,7 and 8 . The average concentration that is on the centre of the symmetry of the garage and $1.8 \mathrm{~m}$ above the ground (on the height of a grown humans head) is equal to around 6560 PPM. Such high levels of the contaminant may lead to increased respiratory rates and be harmful to occupants with breathing problems $[16,17]$.

Figure 7 also shows the velocity vectors within the garage. Because the structure is extremely airtight and the outlet vent is constantly working, more turbulent airflow appears inside of the test object. The contaminants and air no longer flow directly to the outlet but are distributed throughout the object. This leads to the unifying of the average contaminant concentration throughout the garage, while in the previous cases the concentration was mainly elevated directly near the contaminant source and removed immediately by the outlet vent. This poses a larger threat for the occupants if they were to stay in such conditions, especially for those with respiratory problems.

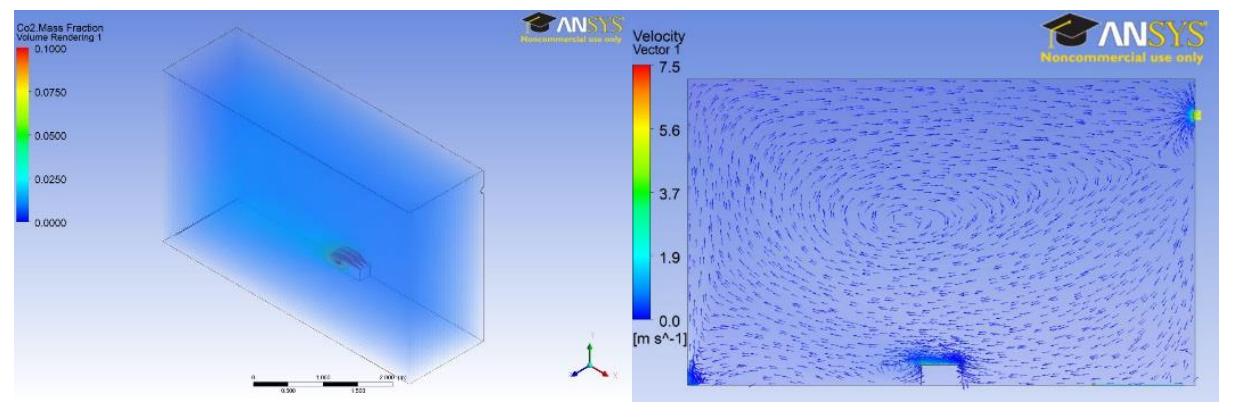

Fig. 6. Results of the $\mathrm{CO}_{2}$ concentration inside of the garage - gasket on both doors
Fig. 7. Velocity vectors of the airflow inside the garage - gasket on both doors.

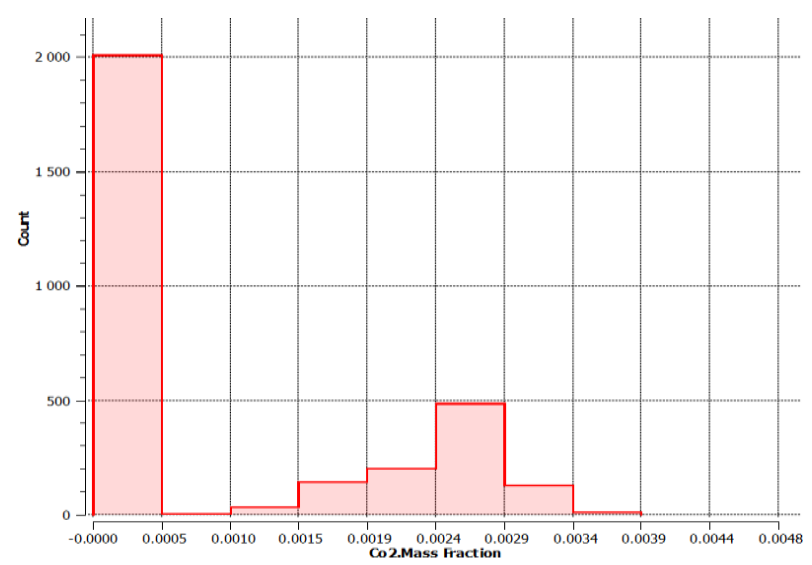

Fig. 8. Leakage of $\mathrm{CO}_{2}$ into the house though the door - gasket on the garage door.

The results from figure 8 show the amount of the contaminant leaking into the house through the door. The results show that the average leakage in this case is equal to 
$0.0023 \mathrm{~kg} / \mathrm{kg} \mathrm{CO} 2$ which is approximately $1500 \mathrm{PPM}$. The sealing of the door does not minimize the contaminant flow through to the building as high concentrations of contaminants still flow into the house.

\section{Discussion}

The simulation using CFD and FEM methods are a valid tool for establishing conditions for future real measurements. They allow omitting cases that generate costs and do not bring useful data for the researcher. The authors, in their previous papers, proved that with correct model in numerical tool the difference between the model and real life object or system are relatively small as is shown in [18] where the AnsysFluent software was used to verify airflow patterns. Other verification of authors FEM and CFD numerical models for the mechanical structures may be found in [19-22].

In this paper CFD applications were used for the estimation of contaminant migration. The current simulations show that there is a large probability of leakages though the garage door when tightening the building structure. However, the concentrations may change with the changing conditions within the garage, e.g. when opening the garage door. In this study only a steady state was taken under consideration to compare and contrast the influence of the car on the air quality.

Additionally, CFD modelling programs like the AnsysFluent software are a valid tool for estimating contaminant migration and airflow patterns. They have been proven to efficiently reflect the conditions within many types of buildings such as garages and the influence of different ventilation methods [8, 12, 23-25]. The validation of such results has proven that the program can reflect the conditions inside of an experimental test object. The next step in the research will be to conduct laboratory experiments by building a laboratory chamber to study the phenomena mentioned in the article

\section{Conclusions}

The aim of the study was to test the influence of a garage on the air quality within the attached house depending on its airtightness. Most garages that depend on a mechanical ventilation system are equipped only with an outlet vent and fresh air is provided by the leakages through the garage door. Due to enhanced airtightness to prevent heat losses; the ventilation system may not provide proper indoor air quality as fresh air may not flow freely into the object. The accumulation of contaminants due to airtightness may cause great risks for the occupants as they can be hazardous for human health when prolonged contaminant exposure occurs.

The garage was connected to a house on the same level and contaminants flew freely with the airflow through the leakages in the closed door. The results of the study showed that the best air quality was when the air freely flowed through the garage door and no gasket was used. The concentration of $\mathrm{CO}_{2}$ was the lowest; the contaminant was removed directly by the outlet fan and did not mix with the fresh air. The worst conditions where when a gasket was used both on the garage door and the door to the house. Not only did the concentration of contaminants that flew into the house increase, but also the contaminant mixed with the fresh air due to increased turbulence of the airflow. This caused the concentration of $\mathrm{CO}_{2}$ to rise not only near the contaminant source, but in the entire volume of the garage.

The results show that the importance of air quality should not be omitted when taking under consideration energy saving strategies in residential households. The simulations prove that a garage attached to a house with increased airtightness may be harmful to 
human health. The results encourage to maintaining the research on the effects of different strategies to both increase the energy efficiency and maintain proper indoor air quality inside residential buildings.

\section{References}

1. L. Pérez-Lombard, J. Ortiz, C. Pout, Energy Build. 40, 3, 394-398 (2008)

2. Directive 2010/31/EU, 13-35 (2010)

3. G. Nirvan, F. Haghighat, L.L. Wang, H. Akbari, Build. Environ. 56, 176-183 (2012)

4. D.N. Sørensen, L.K. Voigt, Build. Environ. 38, 6, 753-762 (2003)

5. M. Marć, M. Śmiełowska, B. Zabiegała, Sci. Total Environ. 573, 767-777 (2016)

6. L'. Mečiarová, S. Vilčeková, E.K. Burdová, J. Kiselák, Int. J. Environ. Res. Public Health 14, 12, 1443 (2017)

7. S. Batterman, G. Hatzivasilis, C. Jia, Atmos. Environ. 40, 10, 1828-1844 (2006)

8. K. Papakonstantinou, A. Chaloulakou, A. Duci, N. Vlachakis, N. Markatos, Energy Build. 35, 9, 933-940 (2003)

9. K. Gładyszewska-Fiedoruk, M. Nieciecki, Energy Procedia 95, 132-139 (2016)

10. T. Gil-Lopez, A. Sanchez-Sanchez, C. Gimenez-Molina, Appl. Energy 113, 622-630 (2014)

11. E. Immonen, Build. Simul. 9, 1, 53-61 (2016)

12. Y. Hajji, M. Bouteraa, A. Elcafsi, A. Belghith, P. Bournot, F. Kallel, Renew. Sustain. Energy Rev. 50, 810-818 (2015)

13. H. Montazeri, F. Montazeri, Renew. Energy 118, 502-520 (2018)

14. D. Al Assaad, C. Habchi, K. Ghali, N. Ghaddar, Build. Environ. 128, 22-32 (2018)

15. M. Andrzejewski, PhD Thesis (2013)

16. K. Kaiser, Rynek Instal. 9, 1-7 (2010)

17. IVHHN, https://goo.gl/awc2hw (access date: 1.01.2018)

18. N. Szczepanik-Ścisło, J. Schnotale, Ciepłownictwo, Ogrzew. Went. 1, 4, 38-42 (2017)

19. Ł. Ścisło, Tech. Trans. - Mech. 2-M, 247-254 (2010)

20. L. Scislo, M.S. Kozien, ICSV21: $20^{\text {th }}$ International Congress on Sound \& Vibration, 13-17 (2014)

21. M.S. Kozień, Ł. Ścisło, Acta Phys. Pol. A 128, 1A, A-56-A-61 (2015)

22. L. Ścisło, M.S. Kozien, XXV International Conference on Theory of Machines and Mechatronic Systems (2016)

23. D. Chen, Build. Environ. 46, 12, 2590-2597 (2011)

24. J. He, E. Kokgil, L. Wang, H.D. Ng, Int. J. Hydrogen Energy 41, 34, 15388-15398 (2016)

25. E. Immonen, Build. Simul. 9, 1, 53-61 (2016) 